\title{
NURSING CARE AND PHYSIOTHERAPY IN THE BURN INTENSIVE CARE UNIT OF THE INDIVIDUAL WITH TOXIC EPIDERMAL NECROLYSIS
}

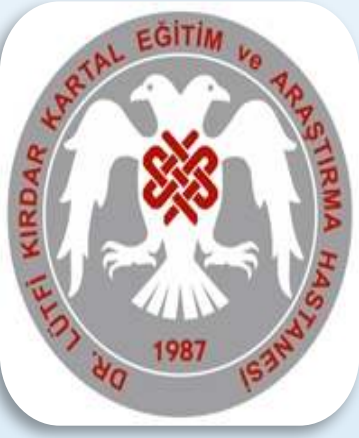

\author{
Mine Seyyah, Özgül Yasan, Gaye Taylan Filinte \\ Unıversity of Health Science Kartal Dr. Lütfi Kırdar Training and Research Hospital, Burn and Wound \\ Center Istanbul, Turkey
}

OBJECTIVE: Stevens-Johnson syndrome (SJS) and Toxic epidermal necrolysis (TEN) are severe adverse cutaneous drug reaction characterized by epidermal loss and multisite mucositis. The aim of nursing care of the patient and physiotherapy process with SJS is to enhance the patient's quality of life.

CASE: 17 years old male patient, no additional history of illness. About 6 weeks of vitamin B treatment and paracetamol applied. When he applied to the emergency room, there were lesions in the oral mucosa and eyes. Tracheal intubation was performed. Body, both upper extremities, Head Primary and common skin rashes were present. Patient was given oral care, perineum care, body cleaning, bed care, every 2 hours. A special silver product was used to reduce lesions and sepsis in the upper body of the patient and changed over the course of the day.

During hospitalization he was extubated 6 times but he was unable to tolerate, Pain, agitation, oral nutrition were closely monitored. It was supported as TPN and enteral for nutrition.

The patient who was extubated again remained intubated for 528 hours. After 35 days in intensive care, the burn service was transferred to the burn service. He was discharged after 16 days in burn service.

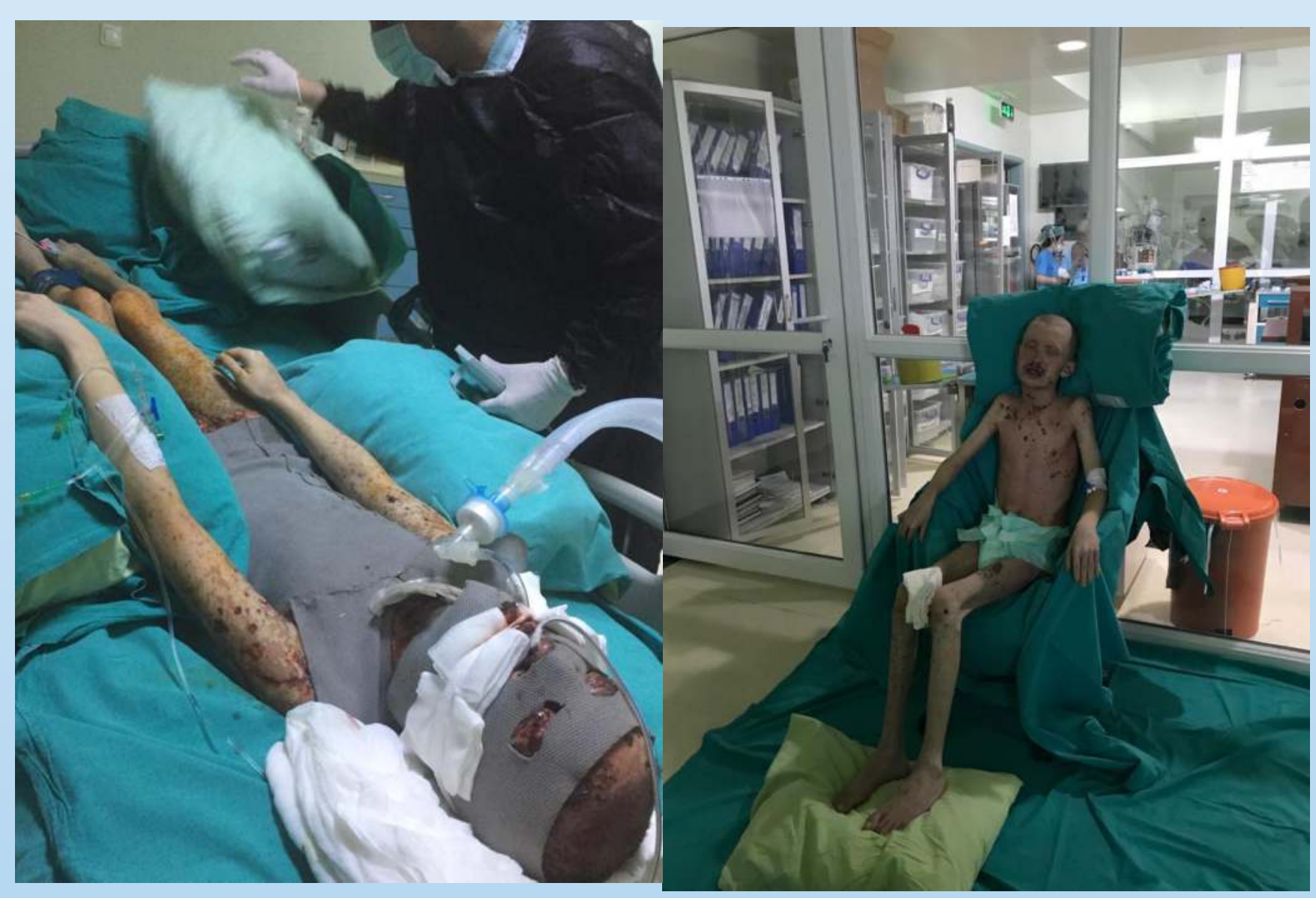

The range of motion of active joints was assessed by goniometric, pain by VAS, muscle strength by manual muscle test, daily life activities and transfer activities by Barthel Index. The physiotherapy program included active respiration techniques, forced expiration technique, respiratory control, diaphragmatic respiratory exercises, in-bed exercises and activities for functional purposes. After rehabilitation, there was an increase in active range of motion (EHA) and functional activity and a decrease in pain. He is now mobilized himself and his daily activities is independent. We think that early physiotherapy practices will reduce the negative effects of immobilization. 